MARGARET JACKSON PRIZE ESSAY 2004

\title{
The invisible man. Artificial insemination by donor and the legislation on donor anonymity: a review
}

\author{
Sharon R Cohen, Guy's, King's and St Thomas' School of Medicine, London, UK \\ Correspondence: Sharon Cohen.E-mail: sharon.r.cohen@kcl.ac.uk \\ Journal of Family Planning and Reproductive Health Care 2004; 30(4): 270-273
}

\begin{abstract}
Until recently, sperm donors have remained anonymous under the 1990 Human Fertilisation and Embryology Act. There has been a distinct international trend towards allowing children access to identifying information about their donor. The UK has followed and, subject to parliamentary approval, children born by donations made after 1 April 2005 will be legally entitled to information revealing the identity of their donor. The lifelong wellbeing of the child created must be the prime consideration in any reform of the law.
\end{abstract}

\section{Introduction}

Dr Margaret Jackson was a pioneer of donor insemination, ${ }_{1}^{1}$ and made a considerable contribution to the now wellestablished practice. Recent figures suggest up to one in six couples experience fertility problems, ${ }^{2}$ and artificial insemination by donor (AID) is now a readily accepted treatment. Nearly 3500 patients are treated with donor insemination in any one year, and more than 800 babies are born as a result. ${ }^{2}$

Should these children know the nature of their conception? Should details of their donor be made available to them? On Wednesday 21 January 2004, the Government announced its plans to abolish donor anonymity from 1 April 2005. ${ }^{2}$

This review describes the history of the practice, the various committees of enquiry over the years and their recommendations, and outlines the evolution of the current British system. Evidence from studies exploring issues associated with sperm donation is used to address whether the concerns that gave rise to anonymous donation are still relevant today, and to consider whether the Government's decision was both timely and appropriate.

\section{AID: a review}

AID was introduced into clinical practice in England in the 1930s and was generally practised in secret. ${ }^{3}$ The first published report about the practice appeared in the British Medical Journal in $1945,{ }^{4}$ causing both outcry and condemnation.

In 1948, a commission was set up to discuss the issues raised by AID, and concluded that it should be considered a criminal offence on religious grounds (an objection to masturbation and a comparison to adultery) and problematic due to the unknown future implications for children born from the practice. 5 Further publications regarding the practice appeared in $1953^{6}$ and $1955^{7}$. The author, Dr Margaret Jackson, established an insemination clinic in Exeter. Between 1940 and 1980 there were 480 births from her clinic. Donors were anonymous and recipients were encouraged to keep their participation in the AID programme secret, especially from their child. ${ }^{5}$

The 1960 Feversham Committee, set up by the Government to examine the legal aspects of AID, suggested that AID may be an acceptable treatment for some couples, but should be discouraged, remarking that "to be born in this way could only be considered a handicap: the practice involves suppression of the truth". 8 However, the demand for AID continued to grow, and in 1968 the treatment became available under the National Health Service, ${ }^{9}$ with a call for follow-up studies by the 1973 Peel Committee. ${ }^{10}$ As insemination had been so successful in animal husbandry, and no AID children were reported in the psychological literature, the practice was assumed to be problem free. 5

In 1982, The Warnock Committee, chaired by Baroness Mary Warnock, was commissioned by the Government to examine the social and ethical implications of reproductive technologies. At this time, gamete donation was occurring without regulation or central record keeping. The donor offspring was considered illegitimate and the donor was considered the legal father. ${ }^{11}$ It was common for the husband to be named as the father on the child's birth certificate, an act considered illegal. 12 Thus, donor anonymity was necessary to protect the donor from legal obligations and grant the husband full paternal rights. ${ }^{13}$

The Warnock Report, published in 1984, approved the practice of gamete donation, recommending "the AID child should in law be treated as the legitimate child of its mother and her husband, where they have both consented to the treatment". ${ }^{14}$ This led to a provision in the 1987 Family Law Reform Act allowing the husband to be named as the child's father. ${ }^{15}$ The report also recommended that donation be anonymous. "Anonymity would give legal protection to the donor, but it would also have the effect of minimising the invasion of the third party into the family. Without anonymity, men would, it is argued, be less likely to become donors". 16

Lengthy parliamentary debates ensued, resulting in the passing of the Human Fertilisation and Embryology (HFE) Act in 1990. Many of the recommendations, including those regarding donor anonymity, were converted into legislation. ${ }^{17}$ Under the regulated service, the donor was to have anonymity and immunity from child support legislation. ${ }^{17}$ Upon reaching the age of 18 years, the child was entitled to non-identifying information (height, hair colour and race) about their donor. By defining legislation in these areas, the 1990 Act contributed to the already growing acceptance of AID. ${ }^{18}$ Most crucially, by recognising that attitudes towards anonymity could change in the future, the Act set up information-gathering structures necessary for a future programme of nonanonymous donation. 9

The Warnock Report ${ }^{14}$ also recommended the creation of a regulatory body for assisted reproduction and human embryo research. Upon the founding of the Human Fertilisation and Embryology Authority (HFEA) in 1991, a Register of Information was introduced, ${ }^{2}$ containing confidential information on all donors and people receiving treatments. The reason for this register was three-fold: (1) A donor could be traced and further donations prevented if a child was found to have a hereditary disorder. (2) Upon reaching the age of 18 years, children could ask the HFEA 
to confirm that they were born by AID. (3) Those intending to marry (including those aged under 18 years) could find out whether they were related to their intended spouse. ${ }^{19}$

In October 2000, a few children born by AID challenged the High Court for the right to identifying information about their biological parents. Lawyers claimed that the law banning disclosure of donor identifying information contravened Article 8 of the Human Rights Act: the right to respect for privacy and family life, and the right to form a personal identity. ${ }^{20,21}$ They also quoted Article 14, an anti-discrimination provision, arguing that donor offspring should have the same rights as adopted children to trace their biological parents. 22

In 2002, the High Court ruled that the 1990 HFE Act did in fact breach Article 8 of the Human Rights Act. ${ }^{23}$ At the time of its passage, a legal safeguard was written into the 1990 HFE Act $^{17}$ stating that a full parliamentary debate, resulting in a primary legislation, would be required to permit access to donor information by children. In December 2001, the Department of Health published a consultation on the provision of information to people born as a result of gamete donation. ${ }^{2}$

On Wednesday 21 January 2004, the Department of Health announced a sweeping reform in the law on donor anonymity. Subject to parliamentary approval, those born as a result of sperm, eggs or embryos donated after 1 April 2005 will gain access to the identity of their donor when they reach the age of 18 years. The new regulations are not retrospective, and any donations made prior to April 2005 will remain anonymous. ${ }^{2}$

The legislative change was influenced by the belief that "the position of donor-conceived people should be aligned more closely with that of adopted people". ${ }^{24}$ In her speech given to the HFEA, the Rt Hon. Melanie Johnson MP, Minister for Public Health, asked: "Is it reasonable for information about their genetic origins that is held on a national database to be withheld from [these children]? Is it equitable that adopted people are able to find out at age 18 who their birth parents are but donor-conceived people cannot be told who their donor was? ... [The Government] have concluded that the interests of the child are paramount". ${ }^{4}$

Internationally, the majority of countries still practise anonymous sperm donation. However, in recent years a trend has developed, allowing children access to identifying information about their donor. ${ }^{25}$ Sweden was the first country to remove gamete donor anonymity in $1984^{26}$ and a number of other countries have since followed suit. 9

\section{Donor anonymity: the arguments}

A common justification for anonymity and secrecy in AID is that they are necessary to protect those involved from perceived societal disapproval and stigma. ${ }^{27,28}$

Dr Margaret Jackson had the foresight to realise that reproduction was not merely a biological event, but also a significant social event. Dr Jackson kept in close, regular contact with the AID couples from her practice. She procured a substantial amount of information about the development of AID children, and their families' wellbeing. Dr Jackson's unique approach created an opportunity to study the social effects of AID. Her research concluded that couples displayed an overwhelming need for secrecy about their AID experience. ${ }^{1}$

Secrecy is said to protect the donor offspring themselves. An English study found that $70 \%$ of birth mothers of AID children justified the decision not to tell their children of their mode of conception on the grounds that secrecy would protect the child from societal stigma and preserve the child's bond with the infertile birth father. ${ }^{29}$ In addition, both birth parents were concerned that the child would be upset by the absence of information about their donor, and thought it best not to say anything. Similar figures were reported in studies conducted on AID couples in Sweden, ${ }^{30}$ despite the offspring's legal entitlement to donor identifying information, and in Holland 31

The large number of couples who decide not to tell their child the method of their conception reflects desire to mimic a natural family. As the child is genetically related to one parent and there has been both a pregnancy and birth, the parents can easily hide the nature of the child's conception and give the impression that, biologically, the child is their own. ${ }^{9}$ AID is accepted "because its deviant characteristics can be largely disguised. By distancing the donor, the appearance of a normal family is preserved." 32

Finally, some believe that access to donor identifying information would create a shortage of donors, who would be discouraged from donating if they knew that their offspring may one day contact them. ${ }^{9}$ However, studies have illustrated this relationship may not be as prevalent as was first assumed. When donor anonymity was abolished in Sweden, the sperm donor profile shifted from young students to mature family men. Despite an initial drop, the number of donors recruited did not exhibit an overall decline, suggesting that the possibility of future contact by offspring had not had the negative impact on donor availability as predicted. ${ }^{26}$

Arguments for the removal of donor anonymity have focused on the donor offspring's best interests and human rights, with the belief that denial of knowledge regarding one's genetic origins can be harmful. ${ }^{28}$

The secrecy surrounding AID can adversely affect individual family members and the family as a whole. The strain caused by secrets in families is thought to build up over time, ${ }^{33}$ and some authors believe that the child can sense the presence of a secret in their family, even if they cannot deduce what it is ${ }^{34}$ In addition, eventual discovery of this deception can irreparably damage trust within the family. 28

However, much of the evidence on the supposed harm caused by ignorance of one's genetic roots comes from adoption studies. Donor offspring are different to adopted children as they are usually genetically related to their mother, and have not been abandoned by their biological parents. Thus, conclusions drawn from such comparisons have been criticised. ${ }^{35}$

The relatively small number of studies undertaken in this area may account for the absence of any conclusive evidence linking ignorance of one's conception or the donor's identity with psychological problems. ${ }^{36}$ Furthermore, it has been difficult to study the effects of donor identification as anonymity has been the dominant model..$^{25}$

Regardless of whether actual harm is caused to a child, many argue that donor offspring have a right to know the truth about their conception. ${ }^{3,27}$ While this information is of varying importance to each individual, the concept of donor anonymity means that donor offspring are never given the opportunity to decide the importance of knowing people with whom they share a genetic connection. This decision is made for them by their birth parents and the legal system. ${ }^{27}$

Moreover, it is not considered sensible medical practice to create a situation where an AID child/adult does not have access to half their family health history, a state that will continue throughout their lives and affect future generations. 37 


\section{AID: the future}

The impact that legislative change will have on future donations is unknown. Evidence from countries that have implemented the removal of donor anonymity may illustrate potential outcomes.

Some fertility specialists are speculating that the already short supply of donor eggs and sperm in the UK could drop further ${ }^{38}$ and the change from anonymity to identification would carry consequences for infertile couples. 5

In 2002, Professor Ian Craft, Director of the London Fertility Centre, stated: "If people who donate want to remain anonymous, I do not think they should be forced to be identified. I think it would definitely lead to a reduction in the number of donors. ... There are enough hurdles in front of would-be parents seeking help without this - fewer donors coming forward would mean they would have to wait even longer". 39

Dr Mohamed Taranissi, Medical Director of the Assisted Reproduction and Gynaecology Centre in London, opposed these views. Dr Taranissi commented that: "There are very good genetic reasons for knowing the identity of a sperm donor. Provided you are not going to add any extra responsibilities in the future for the sperm donor, then I see no reason why their identity should be a secret issue. I don't think it would mean a lack of donations ... It should be part of the child's welfare rights to know who their real father is." 39

Ms Johnson recognised the possible impact on the number of donors coming forward. "It will most probably lead to an initial drop in donor numbers. But we are taking this step in the interests of the children involved - their rights are the prime consideration." 24

Studies investigating the recruitment of sperm donors have demonstrated the main motivating factor for donation to be a strong desire to assist infertile couples. Monetary reward is not a significant motivator, although reimbursement of expenses is important. Donors respond best to advertising campaigns and personal experiences with infertile couples, and have reported that their partner's support is important to them. ${ }^{40,41}$ These studies provide essential information on what actions the Government must take to ensure that donor identification does not adversely affect donor numbers.

Ms Johnson vowed to "fund a campaign for public awareness.... We aim to change the culture, so that people recognise the need and importance of helping others to have families, so that people assume it's the right thing to do, that they can play a role altruistically, that they should encourage others to help". Among the Government's plans to increase public awareness is a fully funded national helpline providing preliminary information for those interested in donating. Ms Johnson emphasised the importance of having excellent websites, offering comprehensive advice and counselling, giving donors early appointments and listening to their needs. ${ }^{24}$

However, given the apparent reluctance of some parents to tell their children of their donor origins, ${ }^{1,29-31}$ the future may dictate that it becomes necessary to make a notation on each donor offspring's birth certificate specifying that they were born by AID. ${ }^{27}$ Baroness Warnock agrees with this idea. "I know there are a considerable number of families where the child is never told that they are a result of sperm donation, and that seems to me to be immoral and wrong. ... The right procedure would be to put on every birth certificate 'by donation', and then it follows from that that the child could not be deceived, and when he is 18 , he can pursue the identification of his father." When asked if she would ever make this recommendation, Baroness Warnock replied: "Yes, I would. I'd like to talk to various paediatricians and I'd like to get some opinions, and then I think we might do something about it". 42

\section{Conclusions}

In recent years, increasing focus on the importance of children's rights has resulted in a greater awareness of the AID child's perspective on donor anonymity. The relevance of arguments made for anonymous donations has diminished, and the Government's announcement to abolish anonymity is considered an enlightened approach to assisted reproduction.

As Baroness Warnock stated: "I think what has changed is the general attitude towards children's right to know their genetic inheritance. ... There has been a shift towards acknowledging the importance of one's genes, but also, I think, and more importantly to a child, of knowing as much as possible about his extended family, his ancestors, and his roots". 42

Whether the Government's decision was timely and appropriate will only be known in 2023, when the first set of AID children born after 1 April 2005 will reach the age of 18 years, and will be entitled to something that those born before them were not - the identity of their biological father.

\section{Acknowledgements}

The author wishes to thank Baroness Mary Warnock and Lord Robert Winston for their time and assistance.

References

1 Snowden R, Thompson W, Joyce DN, et al. The social implications of artificial reproduction. In: Thompson W, Joyce DN, Newton JR (eds), In Vitro Fertilisation and Donor Insemination: Proceedings of the Twelfth Study Group of the Royal College of Obstetricians and Gynaecologists. London, UK: Royal College of Obstetricians and Gynaecologists. London, UK: Press, 1985; 320-328.

2 Human Fertilisation and Embryology Authority website. http://www.hfea.gov.uk.

3 Nachtigall RD. Secrecy: an unresolved issue in the practice of donor insemination. Am J Obstet Gynecol 1993; 168: 1846-1851.

4 Barton M, Walker K, Wiesner BP. Artificial insemination. BMJ 1945; 1: $40-43$.

5 McWhinnie A. Gamete donation and anonymity: should offspring from donated gametes continue to be denied knowledge of origins and antecedents? Hum Reprod 2001; 16: 807-817.

6 Jackson M. Adoption or AID? Proceedings of the 1st World Congress on Fertility and Sterility, New York, NY, USA, 1953; 506-510.

7 Jackson M. A method of concentrating human spermatozoa for artificial insemination. J Fam Welf 1955; 11: 14-18.

8 Home Office and Scottish Home Department, Departmental Committee on Human Artificial Insemination. Report of the Departmental Committee on Human Artificial Insemination 1960 Cmnd 1105. London, UK: Her Majesty's Stationery Office, 1960. Cmnd 1105. London, UK: Her Majesty's Stationery Office, 1960. Frith L. Gamete donation and anony
Hum Reprod 2001; 16: 818-824.

10 The Peel Committee. Annual Report of Council: Appendix V, Report of Panel on Human Artificial Insemination. British Medical Association. Panel on Human Artificial Insemination. BMJ 1973; 2: 3-5.

11 O'Donovan K. What shall we tell the children? Reflections on children's perspectives and the reproductive revolution. In: Morgan D, Lee R (eds), Birthrights. London, UK: Routledge, 1989; 96-114.

12 Smart $\mathrm{C}$. There is of course the distinction dictated by nature: law and the problem of paternity. In: Stanworth M (ed.), Reproductive Technologies: Gender, Motherhood and Medicine. Cambridge, UK: Polity Press, 1987; 98-117.

13 Dewar J. Fathers in law? The case of AID In: Morgan D, Lee R (eds), Birthrights. London, UK: Routledge, 1989; 115-131.

14 The Warnock Committee. Warnock Report: Report of the Committee of Inquiry into Human Fertilisation and Embryology 1984. Cmnd 9314. London, UK: Her Majesty's Stationery Office, 1984.

15 Family Law Reform Act. London, UK: Her Majesty's Stationery Office, 1987.

16 Warnock M. A Question of Life: The Warnock Report on Human Fertilisation and Embryology. Oxford, UK: Basil Blackwell, 1985; 25.

17 The Human Fertilisation and Embryology Act. London, UK: Her Majesty's Stationery Office, 1990.

8 Haimes E. Do clinicians benefit from gamete donor anonymity? Hum Reprod 1993; 9: 1518-1520. 
19 Braude P, Muhammed S. Assisted conception and the law in the United Kingdom. BMJ 2003; 327: 978-981.

20 Dyer C. Offspring from artificial insemination demand father's details. BMJ 2000; 321: 654

21 Dyer C. Pressure increases on UK government to remove anonymity from sperm donors. $B M J$ 2002; 324: 1237

22 Plea from sperm donor children. BBC News Online, 22 May 2002.

23 Court win for donor sperm children. BBC News Online, 26 July 2002.

24 Minister for Public Health, Rt Hon. Melanie Johnson MP. Speech to Human Fertilisation and Embryology Authority. 21 January 2004 http://www.dh.gov.uk

25 Pennings G. The double track policy for donor anonymity. Hum Reprod 1997; 12: 2839-2844.

26 Daniels K, Lalos O. The Swedish insemination act and the availability of donors. Hum Reprod 1995; 10: 1871-1874.

27 Johnston J. Mum's the word: donor anonymity in assisted reproduction. Health Law Rev 2002; 11: 51-55.

28 Landau R. The management of genetic origins: secrecy and openness in donor assisted conception in Israel and elsewhere. Hum Reprod 1998; 13: 3268-3273

29 Cook R, Golombok S, Bish A, et al. Disclosure of donor insemination; parental attitudes. Am J Orthopsychiatry 1995; 65: 549-559.

30 Gottlieb C, Lalos O, Lindblad F. Disclosure of donor insemination to the child: the impact of Swedish legislation on couples' attitudes. Hum Reprod 2000; 15: 2052-2056.

31 Brewaeys A, Golombok S, Naaktgeboren N. Donor insemination

\section{Conference Report/Prize Essay}

Dutch parents' opinions about confidentiality and donor anonymity and the emotional adjustment of their children. Hum Reprod 1997; 12: $1591-1597$.

32 Haimes E. 'Secrecy': what can artificial reproduction learn from adoption? Int J Law Fam 1988; 2: 46-61.

33 Ruyter KW. The example of adoption for medically assisted conception. In: Evans D (ed.), Creating the Child: The Ethics, Law and Practice of Assisted Procreation. The Hague, The Netherlands: Martinus Hijhoff, 1996; 177-194.

34 Sants H. Genealogical bewilderment in children with substitute parents. Br J Med Psychol 1964; 37: 133-141.

35 Golombok S. New families, old values: considering the welfare of the child. Hum Reprod 1998; 9: 2342-2347.

36 Daniels K, Taylor K. Secrecy and openness in donor insemination. Politics Life Sciences 1993; 2: 155-170.

37 McWhinnie A. Ethical dilemmas in the use of donor gametes. Med Law 1998; 17: 311-317.

38 Dyer C. Shortage of sperm donors predicted when anonymity goes. BMJ 2004; 328: 244.

39 Call to end sperm donor anonymity. BBC News Online, 14 May 2002.

40 Lalos A, Daniels K, Gottleib C, Lalos O. Recruitment and motivation of semen providers in Sweden. Hum Reprod 2003; 18: 212-216.

41 Daniels KR. Semen donors in New Zealand: their characteristics and attitudes. Clin Reprod Fertil 1987; 5: 177-190.

42 Cohen SR. Interview with Baroness Warnock. House of Lords, London, UK, 2 March 2004.

\section{CONFERENCE REPORT}

\section{The 8th Congress of the European Society of Contraception (ESC), Edinburgh International Conference Centre, Edinburgh, UK, June 2004}

A record number, in excess of 1500 , of doctors and others, from all over Europe and beyond, gathered at the Edinburgh International Conference Centre (Figure 1) on the occasion of the 8th Congress of the European Society of Contraception (ESC). As well as people from most European countries, I encountered doctors from Chile and Australia. As expected, Edinburgh provided a warm

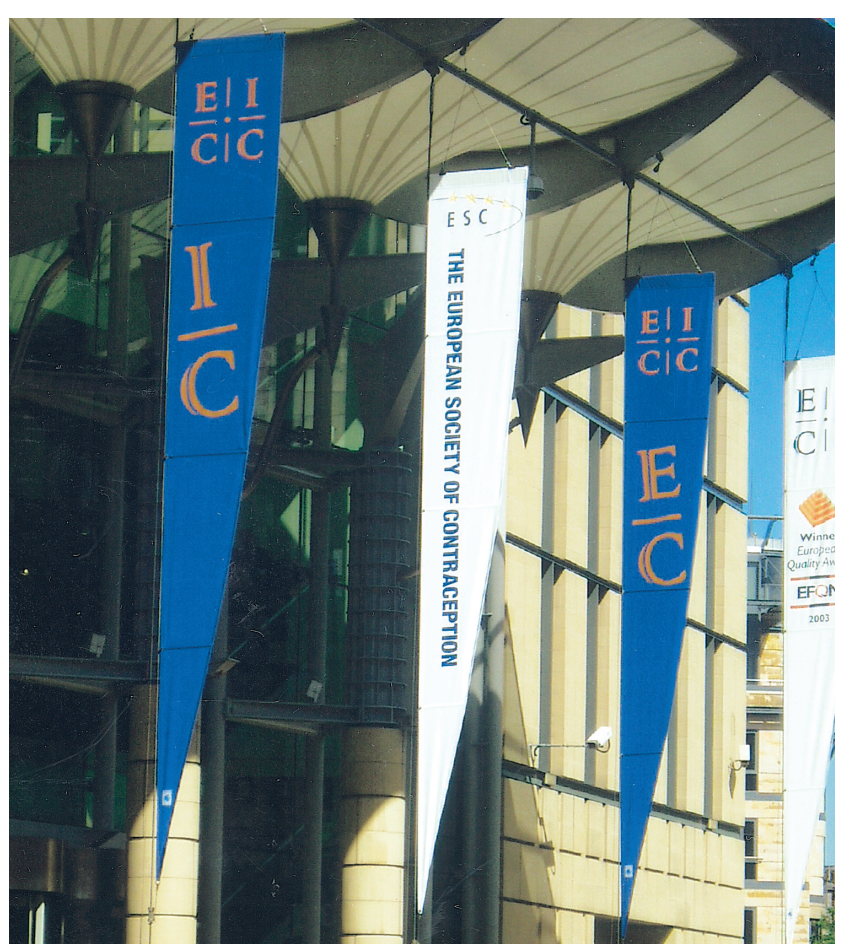

Figure 1 The venue for the 8th Congress of the ESC, the Edinburgh International Centre (photograph courtesy of Michael Cox)

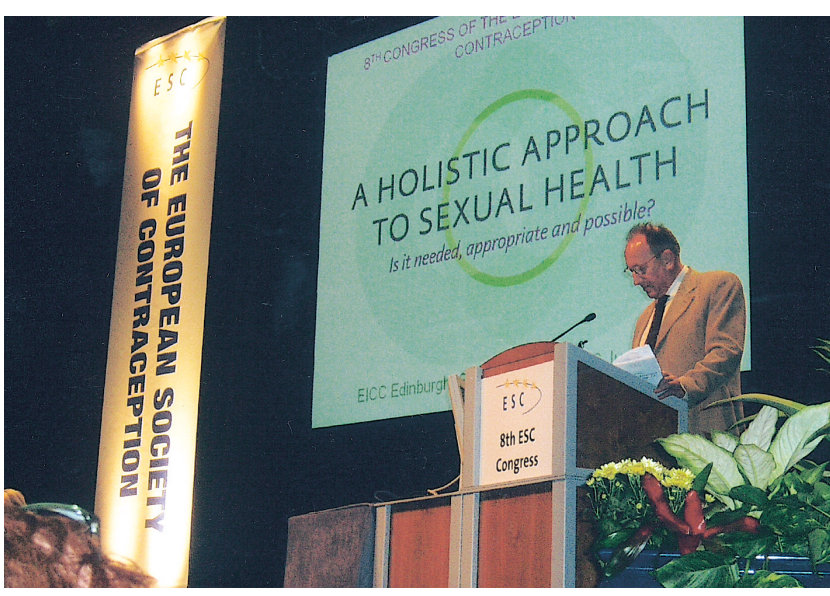

Figure 2 The President of the ESC, Professor Sven Scouby, welcoming delegates to the Congress (photograph courtesy of Michael Cox)

welcome - even small cups of rhubarb and custard at the Opening Reception! (Is this a Scottish custom?)

The ESC was founded in 1988 and since then has held a Congress in various countries every 2 years. The next one will be in Istanbul in 2006. The ESC also organises symposia during non-Congress years and publishes the European Journal of Contraception and Reproductive Health Care. The 2004 Congress was organised in association with the Faculty of Family Planning and Reproductive Health Care. Readers who are not familiar with the ESC can consult its website at http://www.contraception-esc.com/.

At the Opening Ceremony, delegates were welcomed by the President of the ESC, Professor Sven Scouby (Denmark) (Figure 2) and by the President of the Organising Committee, Professor John Newton (UK). The 